\title{
Research on Role and Path of Community Service Center to Participate in Community Governance in South Xinjiang
}

\author{
Wan Xumin \\ Institute of Economics and Management, Tarim University, Xinjiang Alaer Xinjiang, 843300, China
}

Keywords: community service center; community governance, role function, path

\begin{abstract}
This paper analyzes the role function of community service center to participate in community governance and the difficulties faced by community service center to take "service-oriented government", explores the path of community service center to participate in community governance, and have further understanding of community service center and community governance issues, with the hope to provide certain reference for the related contents of research in the future.
\end{abstract}

\section{Introduction}

Urban governance is a key and difficult problem in the process of urbanization development. Moreover, it is a problem that has to be faced. Urban governance involves a lot of contents. From the perspective of administrative division, community governance is a very important content. In the context of the continuous improvement of urban governance, the level of community governance has been significantly improved. However, with the rapid advancement of urbanization, there are more urban problems; the problems faced by community development have also been more, and the complexity has been increasing. In such situation, the traditional community governance has clearly shown its shortcomings. For the current community governance, how to strengthen and improve governance has become the focus. Research [1] shows, in the process of community governance, the resources of all parties in the community can be fully used, coordination can be strengthened, the functions of community service center can be improved, so that it can better serve the work of community governance, effectively improve the level of community governance, and truly reflect the role and function of community service center.

\section{Role function of community service center to participate in community governance}

The objects of community governance work are different and diverse, and different service objects have different demands [2]. In the process of participating in community governance, community service center needs to provide personalized services according to different situations of different residents. At the same time, in the community residents' individual demands and public demands, it is necessary to find a balance point, so that individual demands and common demands can be balanced.

The construction of the platform of mutual help mainly refers to the construction of network platform. The construction of network platform conforms to the development requirements of community governance systematization and network. Through the construction of network platform, the resources are allocated reasonably to the maximum extent, the level of governance is improved, and the quality of service is enhanced. Promoting multi-party linkage requires developing community organizations as much as possible. Through the establishment of community organizations, more residents are encouraged to participate in community governance.

In the process of participating in community governance, community service center should play the role of service provider. In short, it should provide services for community residents, and make community residents feel warm in the process of service, with a sense of belonging. In addition, the cultural history of community should be actively built, and the history of community is deeply rooted in people's hearts. 
On the one hand, community service center should set up the concept of "service-oriented governance" and truly serve the people [3]. Therefore, community service center needs to actively carry out investigation, collect public opinions and conduct in-depth exchanges with residents. On the other hand, the collected public opinions should be classified and summarized, and then scientific and feasible suggestions should be put forward for community governance and construction.

\section{Difficulties faced by community service center to participate in community governance}

The main participants of community service work are social workers, and social work is not highly recognized in the society as far as the current development situation is concerned. According to the survey data [4], among 3,012 surveyed people, more than $70 \%$ of them did not know much about social work, and 50\% of them had a biased understanding of social work and regarded social work as volunteer. Because community residents have low recognition of community service work, it directly hinders the smooth development of community service work. In community governance, they are easily repelled and rejected by community residents, thereby affecting the harmony of community.

In the process of community governance, governance subject is community workstation, which occupies the main position in the work of community governance. With the continuous improvement of community governance, there are more and more subjects in community governance. Besides community workstation, there are other subjects. For community service center to participate in community governance, if other governance subjects can recognize it with the comprehensive understanding, governance work will be more conducted smoothly, but governance subject with community workstation as the main has more complex and diverse attitude towards community service center, directly affecting the effect of governance.

Comprehensive quality of community service center staff to be improved

When community service center is involved in community governance, the most important thing is to provide services, specifically governance services. Therefore, the quality and ability of community service center staff seems to be very important. Practice has proved that the quality and ability of community service center staff remain at a higher level, and then the quality of service involved in community governance will also remain at a higher level. However, due to the imperfect work system of community service center and the inadequacy of staff in working ability and quality, the quality of community governance work has not been improved to a large extent.

\section{Path of community service center to participate in community governance}

Community service center plays a very important role in community governance and exerts a key function. Considering that community service center has some problems in the process of participating in community governance and faces the difficulties of different degree. In this context, when community service center participates in community governance, it must face difficulties and analyze the existing problems, constantly improve its own shortcomings, and actively find more appropriate and more reasonable ways to participate in community governance. From the current governance characteristics of community service center and the problems in practice, the participation of community service center in community governance should start from the following aspects, experiencing the path of "integration $\rightarrow$ service $\rightarrow$ incubation".

The main reason why community service center faces many difficulties in the process of governance service is that it is a subject separated from the new community promoted by government and has not really integrated into the community, without the recognition of community governance subjects and community residents, but with deviation on the understanding of its existence, even some errors [5]. When participating in community governance, community service center should not go off at half cock but start from the perspective of ideology and change their views on themselves. Therefore, community service center needs to integrate into the community in all reasonable and feasible ways, which is also the basis and premise of participating in community 
governance and giving play to the service treatment. At the grassroots community, there are more than one interest subjects, composed of different people, which is more complex. Community service center is exogenous service platform and its most basic work is to know about community, comprehensively grasp various situations and affairs of the community, and then understand and deal with the relationship between the community and its various interest subjects, to win the trust and support of the community as a whole. Specifically, community service center wins trust and support, including "upper" trust and support and "lower" trust and support. "Upper" trust and support refers to the trust and support of communities, street offices and even community governments, and "lower" trust and support refers to the trust and support of general residents of the community [6]. In short, community service center needs to build a service governance "bridge" through services to participate in community governance.

Service is the goal of community service center to participate in community governance and the core of community governance. In participating in community governance, the most important point of community service center is how to provide service for community governance, that is, providing service for community and community residents, and high-quality service. This requires that community service center must adhere to the concept of "service-oriented governance" and play the key point of "service-oriented governance". In the specific operation process, the following relationships need to be handled well:

(1) Balancing the relationship between comprehensive services and professional services. Comprehensive services meet the needs of the whole residents, while professional services meet the needs of specific residents. How to balance the two will directly affect the quality of services. (2) Balancing the relationship between prescribed services and featured services. Prescribed service is a service that must be realized in community governance, and featured service is more inclined to personalized service. On the basis of limited manpower, material resources and financial resources, it is very important to do a good job of featured service, while balancing the relationship between prescribed service and featured service requires some consideration. (3) Balancing the relationship between direct services and integrated resources. In the process of participating in community governance by community service center, it not only includes the service directly provided by community service workers, but also includes the service provided by other resources coordinated by the community service workers. To truly improve the service, it is necessary to balance the relationship between direct service and integrated resources.

The participation of community service center in community governance is not the end point. Providing services to the community and its residents is one of the goals of community service center, but it is not the only goal [7]. In the process of providing governance services, after completing the work of integrating into the community and serving the community, community service center should be able to guide the service objects to participate in community governance, seek the power of the vast number of service objects, and help to better govern the community after completing the integration into the community and serving community. After all, only when the activity and potential of the service objects are maximized, and the service objects become the subject in the social work, can practical problems be solved. Upon carrying out the service work, community service center should consciously cultivate some young backbones; through cultivating community backbone, the original service object is made to become a server, making them more positively and more actively involved in the service, contributing their own strength to community governance, and the strength is the positive power, thinking more from the community governance level.

\section{Conclusion}

In a word, the deepening of urbanization will lead to a series of urban problems, one of which is community governance. Under the background of continuous development of the community, the traditional community governance concept has been difficult to meet the needs of the actual governance work, and it must be adjusted and improved accordingly, so as to seek the help of community service center. 


\section{References}

[1] Liu Xingjing. Research on urban community governance path from the perspective of social interaction theory. Journal of Hubei University of Economics (humanities and social sciences edition), 2017, 14(1):15-17.

[2] Xu Yushan. Service governance: role and path of community service center to participate in community governance. Social Science, 2016, 12(10):99-106.

[3] Jia Lei. Study on the path of social organization to participate in community governance. Deng Xiaoping theory study, 2012, 15(3):27-28.

[4] Long Hongfei. Study on the role of community service center in community governance. Human resource management, 2008, 20 (3):387-388.

[5] Wu Guihong, Chen Xiaoyuan, Fu Xiaofei, et al. Research on the role development of urban community governance - a case study of Guiyang pilot community service center for the reform of urban grass-roots management system. Urban Management Science \& Technology, 2014, 12(2):71-73.

[6] Tan Rihui. Research on the path of social organization to participate in urban community governance. Journal of Shaoyang University (social science edition), 2014,30(5):65-70.

[7] Du Junying. Research on the path of promoting community governance based on community learning's community. Vocational \& Technical Education Forum, 2016,48(24):68-71. 